\title{
Die Moralitates im literarischen Werk Karls IV.
}

\author{
Jana Nechutová \\ (Masaryk University, Brno)
}

\begin{abstract}
"Moralitates" is the least known and least explored among the texts written by Emperor Charles IV. The study presents a critical edition of this text and analyzes its manuscript tradition. Apart from the singular manuscript that has been known in the scholarship so far, another copy is analyzed here (Prague, National Library, XIX B 5). Moreover, the question of the title of the "Moralitates" is discussed here. The study attempts to identify the bearer of the name "Zedekiah" (Sedechias) who is mentioned at the beginning of the text - he seems to be not a biblical figure, but in all probability a mythical Eastern sage. The most significant fact that emerged from the textual analysis is that the first part of "Moralitates" is an almost verbatim translation of the "Liber philosophorum moralium antiquorum" by John of Procida (1210-1298). The study is supplemented by an edition of an epitaph for Sigismund of Luxembourg.
\end{abstract}

\section{Keywords}

medieval Latin literature; literary work of Charles IV; Moralitates; Sedechias; John of Procida; Sigismund of Luxembourg, Epitaph 


\section{"Moralitates" in the Literary Work of Charles IV.}

Unter den Schriften Kaiser Karls IV. gehören die sogenannten Moralitates zu den unbekanntesten; Bohuslav Balbín schweigt in seiner Bohemia docta ${ }^{1}$ noch darüber, und der erste, bei dem ich die Erwähnung der Moralitates finde, ist Heinrich Friedjung im Jahre 1876. In seiner Schrift Kaiser Karl IV. und sein Antheil am geistigen Leben seiner Zeit ${ }^{2}$ ist bereits alles zu finden, was dann die weiteren Autoren wissen, die jedoch diese Kenntnisse nicht aus dem Buch Friedjungs, sondern aus der einleitenden Studie von Karl Wotke zu dessen (bisher einziger) Edition der Moralitates ${ }^{3}$ übernehmen, die dieser Gymnasiallehrer und Privatdozent der Wiener Universität zwanzig Jahre nach Friedjung angefertigt hat. Es verdient zumindest eine Bemerkung, dass Konrad Burdach ${ }^{4}$ schon in den Jahren 1891-1893, also bevor Studien und Edition von Karl Wotke erschienen sind, die Moralitates erwähnt, wobei er die Frömmigkeit des Kaisers als tief mittelalterlich charakterisiert, indem er vom ,asketischen, streng kirchlichen Sinn, der in diesen Schriften redet“, spricht. ${ }^{5}$ Neben der zeitgenössischen alttschechischen Übersetzung von Karls Werk wurden die Moralitates in der modernen tschechischen Sprache durch die Übersetzung von Richard Mašek zugänglich gemacht. ${ }^{6}$ Mit theologischen Inhalten der Moralitates hat sich Bernd-Ulrich Hergemöller befasst: Zuerst widmete er deren Text seine Aufmerksamkeit im Kapitel über Carolus Quartus Latinus, Absatz 4, in seinem Buch mit dem Titel Cogor adversum te: Zur Frage der Tradition des Textes und der eventuellen Vorlagen für die einzelnen Segmente der Moralitates, also zu den Problemen, die wir hier zu lösen versuchen, bringt diese Studie keine neuen Feststellungen, dasselbe gilt auch für seine spätere Studie, die die Moralitates in den Kontext der zeitgenössischen, auch diesen heterodoxen, spirituellen Strömungen stellt. ${ }^{7}$

Friedjung und Wotke wussten und setzten ihre Leser davon in Kenntnis, dass sich die Moralitates in der Wiener Hofbibliothek (der heutigen Österreichischen Nationalbibliothek) befinden: Während es bei Wotke die Handschrift 556 ist, ${ }^{8}$ wo sich die Moralitates

1 Balbíns Schrift Bohemia docta wurde erst 1777 von Raphael Ungar publiziert.

2 VII. Kapitel: „Kirchliches Leben in Böhmen. Legenden-Literatur, Reformbestrebungen“ in Friedjung (1876: pp. 147-148).

3 Einleitung Wotke (1897: pp. 41-59), Edition Wotke (1897: pp. 59-73), Fortsetzung Wotke (1899: pp. 100-110).

4 Burdach (1893: pp. 19-21).

5 An einer anderen Stelle desselben Buches (S. 63), allerdings in einem ganz anderen Zusammenhang, liest man: „Karl IV. ist der Vater der deutschen Renaissance, des deutschen Humanismus geworden, obwohl seinem innersten Wesen der eigentliche Kern der neuen von Petrarca vertretenen Ideen unsympathisch bleiben musste." (Wotke /1897: p. 41/ weist leicht polemisch darauf hin).

6 Die alttschechische Version ed. Emler (1878: pp. 121-130); Übersetzung von Richard Mašek in: Mašek (2000: pp. 67-86).

7 Hergemöller (1999: pp. 293-307) und Hergemöller (2004).

8 In der Handschrift 556 liest man (gemäß dem Katalog der Österreichischen Nationalbibliothek Wien, http:// data.onb.ac.at/rec/AL00174349: Tabulae codicum manu scriptorum praeter Graecos et Orientales in Bibliotheca Palatina Vindobonensi asservatorum, Wien, 1864-1893, Bd. I, S. b95; vgl. Karl Schwarzenberg, Katalog der kroatischen, polnischen und tschechischen Handschriften der Österreichischen Nationalbibliothek, 
tatsächlich befinden, spricht Friedjung von „mehreren Bruchstücken“ in dieser Bibliothek, wobei er aber nur, und zwar irrtümlich, wie es scheint, ${ }^{9}$ eine einzige Signatur, nämlich den Codex Vindob. 619, fol. 53-60, anführt. Darüber hinaus erwähnt Friedjung eine unvollständige, von Bonaventura Piter besorgte Abschrift, die dieser aus einer Prager Handschrift angefertigt hatte und die sich in der Bibliothek der Benediktiner von Rajhrad (Raigern; Sign. H i 15 - so bei Friedjung) befinden soll; Karl Wotke kennt bereits zwei solche Raigerner Abschriften mit den Signaturen H i 5, H e 5, aber heute befinden sich diese Signaturen - nach der neueren Katalogisierung ${ }^{10}$ und nach freundlicher mündlichen Information von Frau Jindra Pavelková, Vizedirektorin der Mährischen Landesbibliothek, die für die Raigerner Handschriften zuständig ist - nicht mehr im Bestand der Raigerner Benediktiner. Die Niederschrift der Wiener Handschrift 556 (in unserer Edition „V“) wird im Katalog auf die Zeitspanne 1385-1390 datiert.

Eugen Hillebrand hält im Verfasserlexikon ${ }^{11}$ die Prager Handschrift, die als Vorlage für die Abschriften von Raigern gilt, für verloren, und die Fachliteratur bezeichnet bis heute die Wiener Handschrift 556 als den einzigen vollständigen Zeugen dieses Werkes Kaiser Karls IV. Dank den modernen Medien, Datenbanken und digitalisierten Katalogen von Bibliotheken, in diesem Fall dank der Digitalbibliothek Manuscriptorium der Handschriftenabteilung der Prager Nationalbibliothek, war es jedoch nicht schwierig, die angeblich verschollene Prager Handschrift zu entdecken. Es handelt sich um die Handschrift XIX B 5 (P unserer Edition), die erst nach der Publizierung von Truhlářs Katalog (dessen Signaturen mit der Abt. XIV enden) aus dem Bestand der Familie Thun-Hohenstein samt anderen Handschriften aus Děčín [Tetschen] ${ }^{12}$ in den Besitz der Prager Nationalbibliothek gelangt ist. In dieser Handschrift befinden sich die Moralitates auf den Blättern 153r-158r gemäß der Nummerierung in der Handschrift (anders als im Manuscriptorium, wo fol. 151r-156r angegeben wird $)^{13}$ und dort liest man auch die anderen Schriften des Kaisers, und zwar die Vita Caroli IV. und den Ordo ad coronandum regem Bohemorum. Die betreffenden Blätter der Handschrift stammen aus der ersten Hälfte des 15. Jahrhunderts. ${ }^{14}$ Die neue, diesmal schon kritische Edition, von der die vorliegende Studie begleitet wird, beruht also auf zwei vollständigen, zeitgenössischen Handschriften.

Während der Arbeit an dieser Edition sind mehrere literaturgeschichtliche und textologische Fragen aufgetaucht. In erster Linie ist es das Problem des Werktitels, Moralitates: dieses Wort als Titel steht weder in der Wiener noch in der Prager Handschrift,

Wien 1972, S B1 (die Angabe über die Moralitates fehlt), weiter: Carolus IV Imperator, Autobiographia Latine, Idem, Moralitates, Ordo coronationis regum Bohemorum, Sermo funebris in Carolum IV Imperatorem.

9 Es handelt sich offensichtlich um die Handschrift 556; der Cod. 619 hat nämlich nur 58 Blätter und enthält Karls Autobiographie (lateinisch) und den Krönungsordo (tschechisch).

10 Švábenský (1981). Vgl. Dokoupil (1966: 10, 16).

11 Hillebrand (1978).

12 Kapras (1904: pp. 424-425).

13 Manuscriptorium, Physische Beschreibung der Handschrift, Absatz Foliierung: „In der Handschrift (sowie in älteren Beschreibungen) erscheint eine Foliierung, die ungefähr 30 Folios mehr hat und einige weitere Fehler enthält. Für die vorliegende Beschreibung wurde eine richtigere Foliierung verwendet."

Für die paläographische Expertise danke ich Herrn Dalibor Havel herzlich. 
weder im Incipit noch im Kolophon, nur in den Rubriken zwischen einigen Segmenten des Textes, wie wir hier gleich sehen werden. In der Prager Handschrift finden wir diese Bezeichnung überhaupt nicht. Die Wiener Handschrift gliedert ihren Text, wenn auch inkonsequent, mit Hilfe von Rubriken (fol. 58v: Sapiencie VI capitulo, fol. 59r: Ezechielis XIV ${ }^{o}$ capitulo, f. 62r: Secundum Lucam, fol. 68r: Omelia). So steht auf dem fol. 59v, am Ende des Exempels über Noe, die Rubrik: Hec est moralizacio domini Karoli regis Romanorum, auf dem fol. 60v, am Ende der Erzählung über Enoch, die Rubrik: Iste sunt moralitates domini Karoli Romanorum et Boemie regis. Abgesehen davon, dass diese Zwischentitel nicht gerade logisch und richtig platziert sind (Wotkes Edition kopiert diese problematische Gliederung), sind diese zwei zuletzt zitierten Rubriken höchstwahrscheinlich der Grund, warum der gesamte Text den Namen Moralitates erhalten hat. Die drei biblischen Stellen, d. h. die über Noe ( $G n$ 9,18-27), über Tubalcain $(G n 4,21-22)$ und über Enoch $(G n$ 5,21-24), hat der Autor nämlich der allegorischen bzw. tropologischen (moralischen) Exegese unterzogen, so dass die drei betreffenden Partien diejenige Struktur, die der mittelalterlichen Gattung Exempel eigen ist, aufweisen: zuerst eine Narratio (hier eine biblische) und dann die Moralisatio (sittliche Deutung) und die praktische Applikation. Mit der - wahrscheinlich unbeabsichtigten - Anwendung der Synekdoche werden hier als Moralisacio oder Moralitas zuerst diese drei Exempla bezeichnet, wie es auch die Rubriken der Wiener Handschrift zeigen; im 19. Jahrhundert haben die Forscher dann für den gesamten Text den Namen Moralitates eingeführt. Es besteht allerdings eine weitere Möglichkeit: Wie wir noch sehen werden, trägt die altfranzösische Bearbeitung des Textes, der dem Anfang von Karls Moralitates entspricht, den Titel Les dictz moraulx des philosophes; es scheint also, dass irgendwo in der handschriftlichen Tradition der lateinischen Version, die als Vorlage für diese französische Übersetzung und noch vorher für das Werk des Kaisers gedient hatte, irgendeine Form des Wortes moralis bzw. moralisatio erschienen sein dürfte.

Ein weiteres Problem, auf das die betreffende Fachliteratur, mit Wotke beginnend, stößt, stellt ein am Anfang des Textes stehender Eigenname dar. ${ }^{15}$ Obzwar einige Forscher aufgrund der französischen Version des Textes, die hier noch behandelt wird, die Möglichkeit einräumen, dass es sich um einen Philosophen dieses Namens handeln könnte, identifizieren sie diesen Sedechias dennoch hartnäckig mit dem alttestamentlichen jüdischen König Sedechias, unter dessen Regierung Jerusalem von Nebukadnezar eingenommen wurde und der, nachdem seine Söhne vor seinen Augen hingerichtet worden waren, samt seiner Familie als Gefangener geblendet nach Babylon gebracht wurde und im Kerker starb; darüber erzählt die Bibel, 2Rg 24 und 25 (vgl. 2Par 36,1013), wo u. a. ausdrücklich Sedechias' moralisch ungenügendes Leben erwähnt wird: et fecit malum coram Domino. Der biblische Sedechias ist also keine positive Gestalt. ${ }^{16}$ Das wurde auch der Grund für die Verlegenheit mancher Forscher und für die von Karl

15 Wotke (1897: pp. 46-47), weiter z. B. Spěváček (1979: pp. 358-359); weitere moderne Forscher, z. B. Kalista (1971: p. 55), oder Bláhová (1987: p. 563), sprechen von dem (mythischen) König Sedechias.

16 Komplizierter ist die Darstellung von Sedechias' Person im Hieremias, was aber in unserem Kontext keine Rolle spielt. Die Aufmerksamkeit, die im Buch Hieremiae dieser Gestalt gewidmet wird, ist Gegenstand zweier Studien von Jiří Beneš in: Prudký et al. (2016: pp. 105-114, 163-171). 
Wotke formulierte Frage, wieso „dieser gottlose Judenkönig zu solcher Auszeichnung gekommen" sei. ${ }^{17}$ Bereits Wotke schlägt aber zwei Jahre später ${ }^{18}$ eine Lösung vor: Der hebräische Name Sedechias bedeutet nämlich iustus Domini, was sogar zum Gemeingut der mittelalterlichen Theologie wurde. ${ }^{19}$ Aber auch das ist wiederum nicht die richtige Antwort: Sedechias, der am Anfang der Moralitates spricht, ist kein König, umso weniger der biblische König Judas, nicht einmal eine biblische Gestalt überhaupt, ${ }^{20}$ sondern ein mythischer Weiser (oder Philosoph), wie wir in der Folge beim Vergleich mit den anderen Derivaten dieses Textes sehen werden.

Richten wir nun unsere Aufmerksamkeit auf die Struktur des Ganzen, die wir in einigen Einzelheiten anders als der ältere Editor sehen, nämlich mit nur neun Segmenten gegenüber Wotkes zwölf: Die drei Exempla, wie auch die beiden längeren Bibelzitate (Weisheit, Ezechiel), halten wir je für eine Einheit. Einige Einzelheiten verdienen überdies einen kurzen Kommentar:

- I - einführend steht hier allgemein, dass Sedechias primus fuit, per quem nutu Dei lex recepta fuit et sapiencia intellecta, dann (nach dem Prädikat dixit) A: kurze Aufzählung der sedecim virtutes, B: vierunddreißig längere Ermahnungen (wieder immer nach dem Prädikat et dixit)

- II - ein neuer Absatz mit einer Initiale, beide Handschriften: In penitencia quid peccatorem considerare opporteat Augustinus in libro De penitencia docet dicens (et ponitur De penitencia distinccione 5 capitulo 1$)^{21} \ldots$

- III - zwei Bibelstellen, die die Pflichten der Herrscher erörtern: A: Sap 6,1-7 mit vielsagender Apostrophe im Incipit (Audite ergo reges et intelligite, discite iudices finium terre), B: Ez 45,8-9. Beide Zitate in den beiden Handschriften mit einer Initiale; Handschrift V mit Rubriktiteln (Sapiencie VI capitulo, Ezechielis XLV capitulo), P nur eine Marginalnotiz: Sapiencie VI capitulo.

- IV - die Exempel: Noe - Tubalcain - Enoch. Alle drei mit Initialen in den beiden Handschriften. Wien hat die Rubriküberschrift über Eigennamen Tubalchayn: Hec est moralizacio domini Karoli regis Romanorum, am Ende nach den Exempeln die Rubrik: Iste sunt moralitates domini Karoli Romanorum et Boemie regis.

- V - Lobpreis Marias: Incipit O Maria, cella Verbi incarnati, die beiden Handschriften mit einer Initiale.

- VI - Meditation über die Fleischwerdung Christi: Christus - Verbum - panis spiritualis auf Grundlage von Io 1,1; Lc 4,4; Io 16,13; Io 6,52; Mt 26,26. Initiale in den beiden Handschriften.

17 Wotke (1897: p. 47).

18 Wotke (1899: pp. 103-104).

19 Die Feststellung von Wotke kann man mit dem Verweis auf Hieronymus, Commentarii in Ezechielem 3,12, ed. F. Glorie, CC SL 75, Turnhout 1964, S. 127, vergleichen. Diese Etymologie wird von Heller (2003: p. 392) bestätigt.

20 Im Alten Testament (2Esr, 3Rg, 4Rg, 2Par, Ier) befinden sich nämlich sechs Personen namens Sedechias, von denen aber keine in Betracht kommen kann: vgl. das Lemma „Sedechiás““ in: Novotný (1992: pp. 858-859).

21 Decretum Gratiani, ed. Friedberg I, col. 1238-40, wo in App.: falso tribuitur Augustino, Lomb. L. IV dist. 16. 
- VII - Homilie: Thema $L c$ 17,11-19 (zehn Aussätzige). Beide Handschriften mit einer Initiale, in Wien die Rubriküberschrift Secundum Lucam. Volltext der Perikope. Es folgt der Text der Homilie mit der Initiale „F“ - Fratres carissimi.

- VIII - Meditation über die Heilsgeschichte mit dem Sturz Lucifers und der Sünde der Ureltern beginnend, bis zur Fleischwerdung Jesu und zu seinem endgültigen Sieg über den Satan. Initiale (Incipit $O$ mira res) in den beiden Handschriften.

- IX - Homilie: Thema Lc 11,27 (Beatus venter, qui te portavit). In der Handschrift Wien die Rubriküberschrift Leccio sancti ewangelii secundum Lucam, die beiden Handschriften haben eine Initiale am Anfang der Perikope und eine am Incipit des Predigttextes. In V vor dem Predigttext die Rubrik: Omelia. In den beiden Handschriften besteht dieses Segment aus zwei Absätzen, von denen auch der zweite mit einer Initiale beginnt.

Aus dieser Aufzählung wird, besonders, wenn man den Inhalt der Texte in Betracht zieht, ersichtlich, dass es sich um Exzerpte aus der Erbauungsliteratur handelt. Sowohl durch den Charakter der Exzerpte als auch durch den Titel Moralitates wurde die Forschung zu einigen Vermutungen geführt: So spricht Burdach ${ }^{22}$ von zwei lateinischen Texten, und zwar vom Lumen animae seu liber moralitatum, das zumeist nur aus Zitaten besteht, und vom Liber moralitatum Lumen fidelis anime aus dem Jahre 1330, einer Exempelsammlung, die fast zwei Jahrhunderte später vom Karmeliter Matthias Farinatoris aus Wien ediert wurde. ${ }^{23}$ Nichtsdestoweniger führt Burdach diese Schriften nicht als Quellen von Karls Moralitates an, er vergleicht nur ihre eindeutig scholastische und asketische mittelalterliche Spiritualität mit derjenigen, die in Karls Exzerpten zum Vorschein kommt. Anežka Vidmanováa ${ }^{24}$ erwägt auch den möglichen Einfluss von Burlaeus' Vitae philosophorum antiquorum. Dem Titel nach bietet sich ein Zusammenhang mit dem Oxforder Theologen Robert Holcot $(\dagger 1349)$ an, dessen Exempelsammlung Moralitates sich häufig mit den Gesta Romanorum berührt und die Kenntnis antiker Autoren bezeugt, meistens handelt es sich aber um moralische Deutungen römischer Autoren, vor allen Senecas und Ovids. Einen ähnlichen Titel, in diesem Fall Opus (bzw. Compendium) Moralitatum, trägt auch eine spätere, erst im Jahre 1528 edierte Bearbeitung der Predigten von Jacobus von Lausanne $(† 1321) .{ }^{25}$ All dies hat jedoch mit Karls Moralitates kaum etwas zu tun.

Speziell die ersten drei Eintragungen in den Moralitates Karls, d. h. die Sprüche von Sedechias, die pseudoaugustinische Passage über die Buße und die zwei Bibelstellen, zeichnen sich durch eine enge Bindung zum Thema der königlichen Moral, der Pflichten eines christlichen Königs und seiner Verantwortung vor den Augen Gottes (manchmal im Sinne des Augustinismus) aus. ${ }^{26}$ Schon Karl Wotke fragte nach dem Material, das hier dem Kaiser als Quelle gedient haben kann, und bereits für den ersten Teil des Textes, die

22 Burdach (1893: pp. 19-20).

23 Koch (1961).

24 Vidmanová (1984: p. 296).

25 Aris (2000: p. 907); Gerwing (2000: p. 259).

26 Darüber siehe vor allem Kalista (1971: pp. 15, 54-55), Spěváček (1979: pp. 358-359), über Karls Spiritualität auch Seibt (1994: pp. 384-388). 
Sedechias-Sprüche, hat er in einem zeitgenössischen französischen Text, Les dictz moraulx des philosophes, eine Parallele entdeckt. Für diese Sammlung ist Guillaume de Tignonville, Berater und Kaplan des französischen Königs Karl VI. und auch Prévôt de Paris (seit 1401) verantwortlich, und Wotke stellt fest, dass der ganze französische Text der Sedechias-Sprüche von Tignonville mit dem lateinischen der Moralitates Karls identisch ist. Er machte sie unter dem Titel Les dits Sedechias philosophe in der Abschrift der Handschrift der Pariser Nationalbibliothek Cod. Franc. 572 (unter Vergleich mit dem Cod. Franc. 812) zugänglich. ${ }^{27}$ Die Existenz der parallelen altfranzösischen Texte hat manche Forscher zu der Vermutung geführt, dass Karls Moralitates zumindest in ihrem ersten Teil als Übersetzung dieses angeblichen, d. h. französischen Originals entstanden sind, wenn auch die Chronologie eigentlich nicht dafür spricht; diese Vermutung wurde durch die Tatsache der engen Beziehungen des Kaisers zum französischen Milieu bekräftigt. ${ }^{28}$

Die bibliographische Katalogangabe eines alten Druckes aus dem Jahre 1531, den Wotke zitiert, führt Guillaume de Tignonville als Übersetzer aus dem Lateinischen an ${ }^{29}$ und schon Wotke wurde also klar, dass das lateinische Original anderswo gesucht werden muss. Zu der Meinung, dass der Urheber des lateinischen Textes Wilhelm von Malmesbury gewesen sei, nimmt er eine kritische Haltung ein, aber weder zur Autorschaft noch zur Textgestalt der angenommenen lateinischen Vorlage sagt er etwas Näheres. Für Zdeněk Kalista, an der angegebenen Stelle seines Werks (hier Anm. 15), ist klar: „(Die Moralitates) sind, wie es scheint, kein authentisches Werk Karls, sondern wiederum ein Stück, das aus ausländischen Schriften übernommen wurde, diesmal aus der mittelalterlichen westeuropäischen Literatur, aus der lateinischen Sammlung der Sentenzen Dicta philosophorum, die dem englischen Mönch Wilhelm von Somerset aus der Abtei Malmesbury - unkorrekterweise, wie ich meine - zugeschrieben wird.“

Heute wissen wir, dass der Autor der lateinischen Version Johannes von Procida (1210-1298) ist. Es handelt sich um einen bekannten Arzt, einen der bedeutendsten Vertreter der Schule von Salerno, der in Diensten Kaiser Friedrichs II. stand. Seinen Liber philosophorum moralium antiquorum haben wir jetzt in einer kritischen Edition von Ezio Franceschini zur Verfügung, ${ }^{30}$ und schon der flüchtige Vergleich ihres Wortlautes mit dem ersten Teil von Karls Moralitates erweist eindeutig die Identität der beiden Texte, was von der Fachliteratur bis heute unbemerkt geblieben ist. Unsere neue Edition der

27 Wotke (1899: pp. 105-108).

28 Vgl. Spěváček (1979: p. 359), Bláhová (1987: p. 563).

29 Bibliothèque Nationale Française, Catalogue général: Les dictz moraulx des philosophes, translatez de latin en françoys par noble homme Messire Guillaume de Tignonville chevalier conseiller et chambellan du roy. http:// catalogue.bnf.fr/ark:/12148/cb32455722t, eingesehen am 23. 7. 2016; diese altfranzösische Version befindet sich in mehreren alten Drucken in vielen Bibliotheken, vgl. z. B. Dis moraulx des philosophes mit fast derselben Überschrift (aus dem J. 1545), The Morgan Library and Museum New York, Medieval and Renaissance Manuscripts, MS M 100. Soweit mir bekannt ist, wurde Tignonvilles Sammlung nicht neu ediert; neben den alten Drucken führt E. Lalou im Lexikon des Mittelalters, s. v. Tignonville, Guillaume, an, dass sich diese altfranzösische Version in mindestens 38 Handschriften befindet. Er führt auch eine provenzalische Übersetzung an (Lalou 2000: pp. 789-790).

30 Francezschini 1932 (id. Venezia, Officine Grafiche G. Ferrari, 1932: pp. 6-196). Zugänglich auch: ALIM - Archivio della latinità italiana del Medioevo. 
Moralitates zieht also auch die Textvarianten dieser Vorlage in Betracht.

Was nun aber überraschend wirken kann, ist die Tatsache, dass nicht einmal dieser lateinische Liber philosophorum moralium antiquorum das Original war. Die Texttradition ist viel komplizierter, als man erwarten könnte, vor allem aber realisierte sie sich in verschiedenen Volkssprachen: Am Anfang steht nämlich der arabische Text Mokhtâr el-Hikam, dessen Autor der arabische Arzt und Philosoph Abu'l Wefa Mubeschs ben Fatik im 11. Jahrhundert war. Dies liest man bei Ezio Franceschini in der Einführung zu seiner Edition, ${ }^{31}$ wobei aber der Editor ausdrücklich darauf hinweist, dass die lateinische Version keine Übersetzung aus dem Arabischen ist, sondern dass es sich um eine Übersetzung aus dem spanischen Text der Dicta mit dem Titel Bocados de Oro handelt.

Der Befund der Überlieferung unserer Texte lässt sich wie folgt zusammenfassen: Arabische Vorlage (11. Jahrhundert) - spanische Version (Bocados de Oro, 1. Hälfte des 13. Jahrhunderts) - lateinische Übersetzung aus dem Spanischen (Liber philosophorum moralium antiquorum) von Johannes von Procida († 1298) - französische Übersetzung aus dem Lateinischen (Les dictz moraulx des philosophes) von Guillaume de Tignonville $(† 1414)$ - altenglische Versionen aus dem Französischen (1450-1500). Und was die Moralitates Kaiser Karls IV. betrifft, haben wir schon gesehen, dass ihr erster Teil die wörtliche Übersetzung des lateinischen Textes ist. Die erwähnte alttschechische Version (vgl. Anm. 6) entstand jedoch als Übersetzung der lateinischen Moralitates Kaiser Karls IV.

Die Tradition der Texte, die wir hier vorgestellt haben, wirft ein neues Licht auf die oben erwähnte Frage des Eigennamens „Sedechias“: In der alten spanischen Version steht (angeblich) nämlich nur „Sed“,32 in der englischen „Zedechye was the first philosopher“. ${ }^{33}$ Der lateinische Übersetzer hat die Bezeichnung „Philosoph“ ausgelassen, indem er den ihm wahrscheinlich unbekannten mythischen Philosophen mit dem ihm dagegen gut bekannten König Judas identifizierte. Obwohl die französische Version eine Übersetzung aus dem Lateinischen ist, kehrt der Übersetzer darin zur Lesung mit „philosophe“ - „Sedechyas fut le philosophe premier“ zurück. Darüber hinaus sind wir, wenn wir den Text der lateinischen Vorlage Karls (Johannes von Procida) weiter lesen, wo ihr Karls Text der Moralitates nicht mehr folgt, ${ }^{34}$ Zeugen einer längeren Serie von Namen von Philosophen, manchmal auch von mythischen, manchmal von solchen mit schlecht verstandenen und verstümmelten Namen: Sedechias folgen nämlich Hermes, Machalquin, Homerus, Zalon, Rabion, Ypocras, Diogenes, Socrates, Plato, Aristotiles,

31 Francezschini (1932: pp. 393-394), vgl. die Einführung zur altenglischen Übersetzung: Sutton (2006). Zugänglich TEAMS, Middle English Texts Series, A Robbins Library Digital Project, http://d.lib.rochester.edu/teams, eingesehen am 31.07.2016. - Eine ältere Edition (ich zitiere nach Suttons „Select Bibliography“, ebenda): Bühler (1941).

32 Sutton (2006: p. 4).

33 Suttons Edition. In der Anmerkung zum Namen „Zedechye“ zitiert Sutton die Ansicht von Margaret E. Schofield (Schofield 1936: p. 206, N. 2): "Schofield posits that Zedechye is either the Egyptian deity Set ... or Seth, the third son of Adam and Eve..." und fügt hinzu, dass "either is possible". Zur letzten Möglichkeit, d. h. zum Namen des dritten Sohnes von Adam und Eva, nämlich Seth, vgl. Gn 4,25-26, wo von Seths Sohn Enos gesagt wird (nach Luthers Bibel): „Zu derselbigen Zeit fing man an zu predigen von des Herrn Namen". 
Alexander, Ptholomeus, Assaron, Loginon, Macdagris, Thesilus, Gregorius, Galienus, und schließlich kommen verschiedene Sprüche mit der Überschrift Sapientium dicta sunt hec vor. Diese Reihe von „Philosophen“ zeigt die identische Struktur (die Sprüche werden meistens mit et dixit eingeleitet), wie es bei dem ersten, Sedechias, der Fall ist, und auch dies überzeugt uns, dass dieser Sedechias einfach nur als der älteste unter den hier behandelten Philosophen auftritt.

Somit ist also die unbestrittene lateinische Vorlage des ersten Teils von Karls Moralitates glücklich gefunden; es muss jedoch eingeräumt werden, dass der Ursprung der weiteren Komponenten unseres Textes unbekannt geblieben ist. Weder für die Exempla (Nr. IV unserer Nummerierung) noch für die kleinen Homilien und Meditationen (Nr. V-IX) haben wir bisher eine Vorlage gefunden. Es ist sogar möglich, dass diese Stücke aus der Feder des Kaisers selbst stammen.

\section{Exkurs - Das Epitaph König Sigismunds}

In der Prager Handschrift der Moralitates, unten auf Blatt 155v (153v), ${ }^{35}$ liest man den Text einer Grabinschrift, dem Inhalt und Namen nach eindeutig Kaiser Sigismund gewidmet:

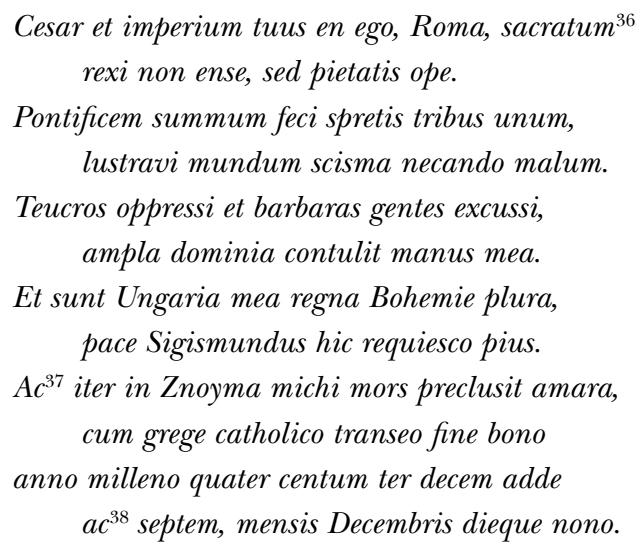

Diese Verse, gleich wie die Bemerkung auf dem folgenden Folio (156r) über den Beginn des Wütens der hussitischen Häretiker im Jahre 1414 (sic), sind von einer anderen, sicher späteren Hand nachträglich hinzugefügt. Zum ersten Mal, soweit ich weiß, sind sie bei Andreas Presbyter von Regensburg, in seiner Fortsetzung der Chronica pontificum et

35 Die Beschreibung der Handschrift in der Datenbank Manuscriptorium führt als einen besonderen Posten (N. 6) auf Fol. 153v, 154r (155v, 156r) „Notae historicae alia manu scriptae“ an.

36 Der Handschrift nach: coma (?) secretum.

37 Der Handschrift nach: Hac.

38 Der Handschrift nach: Hac. 
imperatorum Romanorum, zu lesen, ${ }^{39}$ worüber die Geschichte Kaiser Sigmund's von Joseph Aschbach informiert. In der Fußnote liest man hier auch alle sechs Distichen (12 Verse) dieser Grabinschrift. ${ }^{40}$ Die jüngste Erwähnung findet sich in der Studie aus dem Jahre 2006 von Terézia Kerny: „Die Gebeine König Sigismunds sind spurlos verschwunden und auch sein Grabmal wurde zerstört ... Die Reimdichtung, die als Grabinschrift bekannt ist, stand wahrscheinlich nicht auf dem Grabmal selbst, sondern ist ein fiktives, wesentlich später entstandenes humanistisches Epigramm. " 41 Dann folgen bei Kerny nur die ersten 4 Verse unserer Inschrift und die Fußnote, der zufolge diese in einem alten (1660) Druck von Martin Zeiller Neue Beschreibung des Königreichs Ungarn stehen. ${ }^{42}$ Von einem wesentlich späteren, sogar humanistischen Epigramm kann keine Rede sein: wie wir gesehen haben, ist dieses Epitaph in einer Chronik (Andreas von Regensburg) aus dem 15. Jahrhundert enthalten, und die betreffende handschriftliche Notiz der Prager Handschrift XIX B 5 stammt hochwahrscheinlich spätestens vom Ende desselben Jahrhunderts. Darüber hinaus können wir auf die mangelhafte Metrik der Daktylen, was der humanistischen Dichtung fern liegen würde, hinweisen.

\section{Bibliographie}

\section{Quellen}

Bühler, C. F. (Ed.). (1941). The Dicts and Sayings of the Philosophers: the Translations Made by Stephen Scrope, William Worcester and an Anonymous Translator. London: Oxford University Press.

Emler, J. (Ed.). (1878). Spisové císaře Karla IV. Praha: Sbor Matice české.

Francezschini, E. (Ed.) (1932). Il „Liber philosophorum moralium antiquorum“. Atti del Reale Istituto Veneto di scienze, lettere ed arti, XCI(2), 393-588 (dasselbe 1932, Venezia, Officine Grafiche C. Ferrari, pp. 6-196).

Friedberg, Ae. (Ed.). (1959). Decretum Gratiani: Corpus iuris canonici, pars prior: Decretum Magistri Gratiani (editio Lipsiensis secunda, post Aemilii Ludovici Richteri curas...). Graz: Akademische Druck- und Verlagsanstalt.

Glorie, F. (Ed.). (1964). Hieronymus: Commentarii in Ezechielem 3,12 (CC SL 75), Turnhout: Brepols. Leidinger, G. (Ed.). (1903). Andreas von Regensburg: Fortsetzung der Chronica pontificum et imperatorum Romanorum. In Idem, Quellen und Erörterungen zur beyerischen und deutschen Geschichte, neue Folge, erster Band: Andreas von Regensburg sämtliche Werke. München: G. Himmer.

Mašek, R. (Transl.). (2000). Karel IV.: Literárni dilo. Praha: Vyšehrad.

Schofield, M. E. (Ed.). (1936). The Dicts and Sayings of the Philosophers. A Middle English Version by Stephen Scrope. Ph.D. Diss.: University of Pennsylvania.

Sutton, J. W. (Ed.). (2006). The Dicts and Sayings of the Philosophers [URL http://d.lib.rochester. edu/teams/text/sutton-dicts-and-sayings-bibliography; eingesehen am 23.07.2016].

39 Andreas von Regensburg (1903: p. 497).

40 Aschbach (1845: pp. 397-398).

41 Kerny (2016: p. 477).

42 Zeiller (1660: p. 479, n. 33). Das Buch blieb mir leider unzugänglich. 
Wotke, K. (Ed.). (1897). Moralitates Caroli quarti imperatoris. Zeitschrift des Vereines für die Geschichte Mährens und Schlesiens, 1, 59-73.

Zeiller, M. (1660). Neue Beschreibung des Königreichs Ungarn. Ulm: Kühn.

\section{Fachliteratur}

Aris, M.-A. (2000). Robert Holcot. In Ch. Bretscher-Gisiger, \& Th. Meier (Eds.), Lexikon des Mittelalters (CD-Rom Ausgabe; Vol. 7; p. 907). Stuttgart: Verlag J. B. Metzler.

Aschbach, J. (1845). Geschichte Kaiser Sigmund's (Vol. 4). Hamburg: Friedrich Perthes.

Bláhová, M. (Ed.). (1987). Kroniky doby Karla IV. Praha: Svoboda.

Burdach, K. (1893). Vom Mittelalter zur Reformation (Vol. I). Halle: Weidmann (erweiterter Abdruck aus dem Zentralblatt für Bibliothekswesen, Jahrgang 1891).

Dokoupil, V. (1966). Soupis rukopisů knihovny benediktinů v Rajhradě. Praha: Státní pedagogické nakladatelství.

Friedjung, H. (1876). Kaiser Karl IV. und sein Antheil am geistigen Leben seiner Zeit. Wien: Braumüller.

Gerwing, M. (2000). Iacobus von Lausanne. In Ch. Bretscher-Gisiger, \& Th. Meier (Eds.), Lexikon des Mittelalters (CD-Rom Ausgabe; Vol. 5; p. 259). Stuttgart: Verlag J. B. Metzler.

Heller, J. (2003). Výkladový slownik biblických jmen. Praha: Vyšehrad.

Hergemöller, B.-U. (1999). Cogor adversum te. Drei Studien zum literarisch-theologischen Profil Karls IV. und seiner Kanzlei. Warendorf: Fahlbusch Verlag.

Hergemöller, B.-U. (2004). Black Sabbath masses. Fictitious Rituals and Real Inquisitions. In Ch. Aufrath, \& L. T. Stuckenbruck (Eds.), The Fall of Angels (pp. 176-191). Leiden: Brill.

Hillebrand, E. (1978). Karl IV. In K. Ruh et al. (Eds.), Die deutsche Literatur des Mittelalters. Verfasserlexikon (Vol. 4; pp. 994-999). Berlin - New York: De Gruyter.

Kalista, Z. (1971). Karel IV. Jeho duchovni tvářr. Praha: Vyšehrad.

Kapras, J. (1904). Rukopisy Děčínské. Časopis Musea královstvi Českého, 78, 340-344, 423-430.

Kerny, T. (2016). Begräbnis und Begräbnisstätte von König Sigismund. In I. Takácz (Ed.), Sigismundus rex et imperator. Kunst und Kultur zur Zeit Sigismunds von Luxemburg 1387-1437. Ausstellungskatalog (pp. 475-479). Budapest - Luxemburg: Philipp von Zabern Verlag.

Koch, J. (1961). Farinatoris, Matthias. In Neue Deutsche Biographie (Vol. 5) [Onlinefassung; URL: https://www.deutsche-biographie.de/gnd100970028.html\#ndbcontent, eingesehen am 23.07.2017].

Lalou, E. (2000). Tignonville. In Ch. Bretscher-Gisiger, \& Th. Meier (Eds.), Lexikon des Mittelalters (CD-Rom Ausgabe; Vol. 8; pp. 789-790). Stuttgart: Verlag J. B. Metzler.

Novotný, A. (1992). Biblický slovnik. Praha: Kalich.

Prudký, M. et al. (Eds.). (2016). Obtižné oddily zadnich proroků. Kostelní Vydří: Karmelitánské nakladatelství.

Seibt, F. (1994). Karl IV. Ein Kaiser in Europa 1346-1378. München: Süddeutscher Verlag.

Spěváček, J. (1979). Karel IV. Život a dilo (1316-1378). Praha: Svoboda.

Švábenský, M. (1981). E6 Benediktýni Rajhrad, sv. 5: Opatský archiv sign. G-H (die Archivhandschriften). Brno.

Vidmanová, A. (1984). Karel IV. a latinská literatura v Čechách. In V. Vaněček (Ed.), Karolus Quartus (pp. 291-303). Praha: Universita Karlova. 
Wotke, K. (1897). Moralitates Caroli quarti imperatoris. Einleitung. Zeitschrift des Vereines für die Geschichte Mährens und Schlesiens, 1, 41-58.

Wotke, K. (1899). Zu den „Moralitates Caroli quarti imperatoris Nr. I“. Zeitschrift des Vereines für die Geschichte Mährens und Schlesiens, 3, 100-110.

prof. PhDr. Jana Nechutová, CSc. / nechutov@phil.muni.cz

Arna Nováka 1, 60200 Brno, Czech Republic 


\section{Caroli Quarti imperatoris Moralitatum editio critica}

\section{RATIO EDENDI}

Moralitates ita dictas, quarum compilator Carolus Quartus, Romanorum imperator et rex Bohemiae, opinione communi habetur, Carolus Wotke primus anno 1898 iuris publici fecit editione elaborata secundum codicem manu scriptum Vindobonensem (Bibliotheca Austriaca Nationalis 556), qui usque hodie unicus, in quo Moralitatum textus Latinus ad nos pervenisset, putabatur. Editor vero etiam apographis recentioribus duobus in bibliotheca monasterii Benedictinorum in Rajhrad temporibus eius asservatis et verisimiliter a Josepho Bonaventura Piter, huius monasterii priore, curatis, usus est, quae apographa hodie desiderantur. Carolus Wotke tamen lectores editionis suae attentos fecit apographorum horum archetypum inter codices manu scriptos Pragenses quaerendum esse, exemplari hoc interdum ignoto. Quod auxilio bibliothecae electronicae, cui nomen est Manuscriptorio et quae ad Bibliothecam Nationalem Pragensem spectat, in codice manu scripto huius Bibliothecae XIX B 5 nuper invenimus, qui in possessione familiae Thun-Hohenstein in Děčín fuerat, antequam in Bibliothecam Nationalem Rei publicae Bohemicae venit.

Quae cum ita sint, pro Caroli Moralitatibus critice edendis duo codices manu scripti nobis ad manus erant. Nam codex uterque eiusdem et fere aetatis atque temporis est, et lectiones invicem simillimas praebet, Carolum Wotke nostrum praedecessorem sequentes codicem Vindobonensem 556 fundamentum editioni nostrae statuimus. Cuius codicis et modum scribendi plene retinuimus.

Lectiones variae apparatu critico exhibitae codicis Pragensis sunt. Notamus interdum et modum legendi ab editore Carolo Wotke adhibitum, deinde paucas tantum de lectionibus textuum, qui Moralitatibus exemplar steterunt (Liber philosophorum moralium antiquorum, Decretum Gratiani, Bibliae sacrae versio Vulgata), denique emendationes duas, quas in versione sua moderna Moralitatum Richard Mašek proposuit. Quamquam apparatum criticum plenum atque integrum creare animo habuimus, scripturas a codice primario diversas, quae modum scribendi solum attinent, apparatus noster minime significat. Quod ad locos Bibliae in textu occurrentes, ii, qui de verbo ad verbum cum lectione versionis Vulgatae concordant, litteris Italicis et sine apicibus, soluti vero et liberiores litteris communibus, plerumque apicibus inclusi, scripti sunt.

\section{CAROLI MORALITATUM CODICES}

V codex manu scriptus Bibliothecae Austriacae Nationalis Vindobonensis 556, fol. 53r -69r (saec. XIV exiens).

P codex manu scriptus Bibliothecae Nationalis Rei publicae Bohemicae (Praga) XIX B 5, fol. 153r-158r / 151r-156r (saec. XV iniens). Folia dupliciter notantur, secundum tam codicis manu scripti quam „Manuscriptorii“ databaseos numerationem. 


\section{EDITIO}

Wo Karl Wotke, Moralitates Caroli IV. imperatoris, Zeitschrift des Vereines für die Geschichte Mährens und Schlesiens 1, 1897, p. 41-59 praefatio, p. 59-73 editio.

\section{TEXTUUM AUXILIARIUM EDITIONES}

L - Il „Liber philosophorum moralium antiquorum“ a cura di Ezio Franceschini, in: Atti del Reale Istituto Veneto di scienze, lettere ed arti, a.a. 1931-1932, XCI, 2, p. 393-588 (dasselbe Venezia, Officine Grafiche G. Ferrari, 1932, p. 6-196).

Fr - Corpus iuris canonici I, Decretum Gratiani, ed. Aemilius Friedberg (post Ludovici Richter curas), I, Decretum Magistri Gratiani, zuletzt New Jersey 2000, col. 1238-40.

\section{VERSIONES BOHEMICAE:}

(Versio prisco-Bohemica) Josef Emler, Spisové císaře Karla IV., Pragae 1878, p. 121-130 Richard Mašek, in: Karel IV. Literární dílo, Pragae 2000, p. 67-86.

\section{TEXTUS AUXILIARES}

L Libri philosophorum moralium antiquorum (editio critica E. Franceschini)

Fr Corpus iuris canonici, decretum Gratiani (editio G. Friedberg)

\section{De iis, quae de Caroli Moralitatum textu ad tempus praesens nota sint,}

alio loco scribebamus, hac in praefatione graviora tantum repetenda sunt in usum lectoris Moralitatum hic editarum:

1. Ezio Franceschini iam anno 1932 auctorem textus Latini opusculi (in Moralitatum primam partem ad verbum assumpti) Libri philosophorum moralium antiquorum (vide supra, L) Iohannem de Procida (saec. XII) exploratum habuit, simulque demonstravit archetypum sententiarum harum Arabice conscriptum (saec. XI) et per consequens Hispanice versum esse; de quo tenore Hispanico demum translatio Latina Iohannis de Procida exorta est.

2. Codex manu scriptus Caroli Moralitates integras continens usque tempora nostra codex Vindobonensis 556 (vide supra, V) unicus notus erat, cum hodie et codicem alterum, in Bibliotheca Nationali Rei publicae Bohemicae (Praga) sub signatura XIX B 5 asservatum (vide supra, $\mathbf{P}$ ), noverimus.

3. Sedechias, cuius hoc nomen in exordiis omnium textuum pertinentium in versionibus diversis legitur, non huius nominis regalis persona Veteris Testamenti (2Reg 24 et 25), sed primus tantum de sapientum serie, qui in textu originali primario unus post alterum sententias suas proferunt, existit.

4. Lectoris benivoli animum advertere necessarium ducimus, quod titulum vulgo usitatum opusculi huius, „Moralitates“ videlicet, neuter codicum manu scriptorum usque nunc cognitorum praebet. 


\section{$<\mathrm{I}>$}

(V 53r, P 153r) "Sedechias primus fuit, per quem nutu Dei lex recepta fuit et sapiencia intellecta.

Dixit ergo Sedechias, quod credens quivis habere debet in seipso sedecim virtutes:

Prima est Deum cognoscere et angelos suos. Secunda est discrecio boni et mali, bonum ad operandum, malum ad vitandum. Tercia est obedire regi, quem Deus loco et vice sui ordinat super terram dans ei potestatem in populo. Quarta est honorare parentes. Quinta est benefacere hominibus iuxta possibilitatem suam. Sexta est pauperibus elemosinam erogare. Septima est tueri alienigenas. Octava est niti vehementer ad servicia Dei. Nona est vitare fornicactiones. Decima est habere pacienciam. Undecima est esse veridicum. Duodecima est esse iustum. Terciadecima est esse liberalem. Quartadecima est offerre sacrificia Deo propter beneficia populo suo collata. Quintadecima est regraciari Deo propter eventus, qui iugiter eveniunt in mundo. Sextadecima est esse verecundum et temperatum et modice contencionis.

Et dixit, (V 53v) quod prout decet regiam dignitatem populum sibi subiectum esse obedientem ei, sic decet, ut sit rex studiosus circa statum eorum plusquam circa suum, quia sic est ipse penes eos sicut anima penes corpus. Et dixit: Si rex cogitat adunare thesaurum per extorsionem et iniusticiam, cogitat, quod non est veritas, quia non aggregatur sic thesaurus nisi per depopulacionem terre. Et dixit: Si rex obmittet investigare populi sui facta, milicie sue et inimicorum, non erit uno die securus de regno suo. Et dixit: Quam bene est populo, cuius rex est bone discrecionis et boni consilii et sapiens in sciendis, et quam male est ipsi, quando aliquid predictorum deficit ei! Et dixit: Cum rex despiciet aliquid modicum de hiis, que facere debet, augebitur illud sicut in debili infirmitas corporis, cui si non occurritur cum medicina, magnificabitur, et totum corpus molestabit. Et dixit: $\mathrm{Si}$ rex eludatur adulacionibus inimici et dulcibus verbis non habendo respectum ad opera ipsius, non erit securus, quin subito invadatur ab eo, sicut illi, qui leonis saltu subito et exinproviso invaduntur, non possunt evadere mortem. Et dixit: Interest regis informare filium scienciis, (V 54r) qualiter suum regnum conservet et qualiter sit rectus in populo suo et qualiter dirigat miliciam suam, nec permittat multum uti venacione aut aliis vagacionibus, et instruat eum loqui composite, et vitare faciat vanitates. Et dixit: Interest regis, quod sua beneficia in bonis viris appareant et in

\footnotetext{
4 quivis] om. L; I| habere debet] debet habere P || 7 bonum] boni L; || malum] mali L; || vitandum] evitandum P || 8 ordinat] ordinavit L || 9 benefacere] beneficare L || 10 alienigenas] alienigenas et peregrinos L || 11 niti] inniti L || 12 Duodecima] duodecimam L || 15 in] om. P || 18 ei] cum siglo omissionis P; || sic] sicut P; sit rex] rex sit P || 19 eos sicut] ipsos sicud P || 20 adunare thesaurum] adiuvare thezaurum P || $\mathbf{2 0}$ cogitat] cogitet L || $\mathbf{2 2}$ populi sui] sui populi $\mathrm{P}$ || $\mathbf{2 4}$ sapiens] sapientis V; || sciendis] scienciis L || $\mathbf{2 5}$ aliquid] aliquod P || 27 molestabit] molestabitur L; || dixit] || super dixit P || 32 sit] om. P || 32 miliciam] maliciam P, Wo || 33 vagacionibus] nacionibus P; || loqui] || eloqui L || 34 / 35 Et - nitantur] om. P
}

2 / 84 Sedechias - operibus] Iohannes de Procida, Liber philosophorum moralium antiquorum, p. 398-402 
35 hiis, que scire nituntur, ut ob hoc ad predicta proficere melius nitantur. Et dixit: Interest regis, cum vult sibi serviri ab aliquo de suo ministerio, scire prius mores ipsius, et qualiter se gubernet, et domum suam, (P 153v) et socios; et si perceperit eum esse bonorum morum, gubernatorem status sui et observatorem legis et tollerare pacienter, qui contingunt, sinistros eventus, faciat sibi serviri ab eo, si non

40 detestatur eum. Et dixit: Purum amicum diligentem te scio meliorem fratre et patre et matre optante mortem tuam, ut hereditet bona tua. Et dixit quodlibet appetere suum simile. Et dixit: Qui non mansuescit vel acquiescit castigacione blanda, fac eum mansuefieri correpcione turpi vel aspera. Et dixit: Maiores divicie sunt sanitas corporis, et maior alacritas est satisfaccio cordis. Et dixit: Obediencia ex amore 45 est firmior quam (V 54v) obediencia ex dominacione et metu. Et dixit: Experiencie efficiunt bonas castigaciones, et aspectus ad fines rerum bonam efficit fidelitatem. Et dixit: Melius est in hoc mundo et nobilius fama bona, et in alio mundo exclusio a pena. Et dixit valencius esse tacere quam loqui cum ignorante, et solitudinem querere quam iungere se malis. Et dixit: Quando rex est maleficus, melius est ei, qui 50 non noscit eum, quam qui magnum habet locum cum eo. Et dixit, quod melior est homo sterilis quam habens filium ineptum. Et dixit melius esse stare cum sapiente paupere quam cum divite ignorante. Et dixit: Per sapienciam acquiritur humilitas, bona voluntas, pietas et privacio peccatorum. Et dixit: Non recte agit, qui querit sapienciam non legendo et non laborat studens in eadem acquirenda; et ille, qui 55 cogitat eam habere cum aliqua inhabilitate, est ignorans. Et dixit: Qui deficit in eo, quod tenetur Creatori suo, multo magis deficit in omnibus aliis operibus bonis. Et dixit: Non credas illi, qui dicit se scire veritatem et facit contrarium eius. Et dixit: Sicut pueri nitentes comedere dulcia si prohibeantur, non obmittunt illa comedere, ita igno(V 55r)rantes et diligentes se appetitu corporali non esuriunt nec vitam 60 diligunt nisi propter se, et sapientes non diligunt vitam nisi ut bona operentur, et dimittunt delectaciones mundi, quia nocive tantum sunt diversarum operacionum et voluntatum et similium formarum. Et dixit: Qualiter coequari possunt hominum opera, qui conantur ad profectiva et perpetua prosequenda, cum operibus illorum, qui non nisi in obtinendis suis voluptuosis exerciciis innituntur? Quasi diceret: 65 nullo modo possunt coequari. Multum interest inter illum, qui nititur inquinare se inmundiciis in hoc mundo nocivis et in alio, et inter illum, qui nititur in deposito

35 que] qui L, Mašek || 36 cum] ut cum L || 38 gubernatorem] gubernat rem L || 39 tollerare] toleret L || 40 detestatur] detestetur L || 40 scio] scito L; || et ${ }^{2}$ ] ac L || 41 optante] obtante L || 43 mansuefieri correpcione] assuefieri correctione L || 44 et] om. P || 45 est firmior] firmior est L || 45 dominacione] donacione L || $\mathbf{4 8}$ esse] est L || $\mathbf{5 0}$ qui - locum] ei qui magnum locum habet L || $\mathbf{5 0}$ / $\mathbf{5 1 ~ E t ~ - ~ i n e p t u m ] ~ o m . ~}$ L || 51 esse] est esse V, est L || 51 / 52 sapiente paupere] paupere sapiente P,L || $\mathbf{5 5}$ aliqua inhabilitate] quadam habilitate L || 58 nitentes] utentes L || 61 nocive tantum] nocent tantum P; nocent tamen L || 63 profectiva] opera perfectiva L || 64 / 65 Quasi - coequari] om. L || 66 nititur - deposito] inde nititur posito $\mathrm{V}, \mathrm{P}$, Wo; emendavi secundum $\mathrm{L}$

41 / 42 quodlibet - simile] cfr. Aristoteles Latinus, Guillelmus de Moerbeka translator, De coelo et mundo 4,3; Bekker 310a; Iacobus Veneticus translator, De anima 1,5; Bekker 410a; cfr Hamesse, Auctoritates Aristotelis, n. 141, p. 242; Ethica Nicomachea, Bekker 1155b 
firmato in celis. Et dixit: Non reputatur studiosus, qui obmittit iuvativa et laborat in nocivis. Et dixit: Amara et aspera sapientes tollerant, quasi sint dulcia ut mel, eo quod sciunt finem illorum esse iuvativum. Et dixit: Quam bonum est hiis bene facere, qui merentur, et quam utile, et quam malum est non merentibus et inutile, quia qui hoc facit, perdit laborem suum. Nam qui bene facit non merentibus, est ut pluvia in arena, que ibi perditur. Et dixit: Felix est, cui noctescit et diescit faciendo quod convenit, et (V 55v) qui non accipit ex mundo nisi id, quo excusari non potest, et qui operatur bona et prohibet mala, dum vivit in mundo. Et dixit: Non decet iudicare hominem ex dictis, immo ex operibus, quia dicta pro maiori parte vana sunt, opera vero consecuntur commoda et dampna. Et dixit: Cum elemosina datur debilibus indigentibus, prodest manifeste, sicut (P 154r) medicina, que convenienter offertur infirmis, sanat; et elemosina data non egentibus est sicut medicina disconveniens infirmo oblata. Et dixit: Qui elongatur ab ignorantibus, elongatur a sordibus, et facit quiescere visum et auditum suum ab ipsis. Et dixit: Decencius est toto tempore vite hominis, quod expenditur in servicio Dei bona operando, et mediocre est, quod expenditur in necessariis, quibus excusari non potest in vita, sicut in comedendo, bibendo et dormiendo, decurando infirmitates contingentes; et peius est, quod expenditur in malis operibus.”

$<$ II $>$

In penitencia quid peccatorem considerare opporteat Augustinus in libro De penitencia docet dicens (et ponitur De penitencia Distinccio V caput 1): "Consideret qualitatem (V 56r) criminis in loco, in tempore, in perseverancia, in varietate persone, et quali hoc fecerit temptacione, et in ipsius vicii multiplici execucione. Opportet enim penitere fornicantem secundum excellenciam sui status aut officii, aut secundum modum meretricis, et in modo operis sui, et qualiter turpitudinem suam egit, si in loco sacrato, aut cui debent excellenciam fidei, ut domus dominorum, et aliorum multorum, si in tempore oracioni constituto, ut festivitates sanctorum et tempora ieiunii. Consideret, quantum perseveraverit, et defleat, quod perseveranter peccavit, et quanta virtus fuerit in pungnacione. Sunt, qui non solum non vincuntur, sed ultro se peccato offerunt, nec expectant temptacionem, sed preveniunt voluntatem. Et pertractet secum, quam multiplici accione vicii delectabiliter peccavit. Omnis ista varietas ostendenda et confitenda et deflenda, ut, cum cognoverit, quod peccatum est multum, cito inveniat Deum propicium. In cognoscendo augmentum inveniat se, cuius etatis fuerit,

67 iuvativa] innativa $\mathrm{P}$, Wo, innociva Mašek || 69 iuvativum] innativum P, Wo; innocivum Mašek || 71 est] om. $\mathrm{P}|| 72$ cui] qui L || 73 et $^{1}$ ] et faciendo V, P, Wo; emendavi secundum L || 73 quo] quod L || 76 consecuntur] secuntur $\mathrm{P}$ || $\mathbf{7 8}$ sanat] eos sanat L || 78 / $\mathbf{7 9}$ disconveniens infirmo] disconvenienter infirmis L || $\mathbf{7 9}$ elongatur - ignorantibus] om. L || 80 ipsis] ipsis felix est L || 80 toto] ex toto L || 81 mediocre] mediocriter P || 83 decurando] et curando L || 95 domus] dominus V, P domus Fr, Wo; emendatum secundum Fr

88 / 89 Augustinus - penitencia] Augustino ab autoribus medii aevi perperam attributum, cfr. e.g. Petrum Lombardum, Sent. IV, d. 16, c.2 || 90 / 176 Consideret - vitam] cfr. Decretum Gratiani, De pen. D. 5 c. 1, Friedberg I, col. 1238-1240 
cuius sapiencie et ordinis, et statum omnem alterius non peccantis. Immoretur in singulis istis et senciat modum criminis purgans lacrimis omnem qualitatem

105 vicii et (V 56v) defleat virtutem, qua interim caruit. Dolendum est et dolore purgandum est non solum quia peccavit, sed quod se virtute privavit, nam licet speret se consecuturum veniam, dolere tamen potest, quia non promeruit, unde remunerari confidat. Anxietur et doleat, quod modo effugiens de preteritis

110 penam miser non inde expectat gloriam, cuius omne tempus, quoniam tempus brevissimum est, debuit decertavisse ad consequendum premium.

Defleat eciam, quoniam offendens in uno factus est omnium reus: ingratus enim extitit, qui plenus virtutibus Deum non omnino timuit; in hoc enim quisque peccator fit culpabilior, quo est Deo acceptior. Ideo enim Adam plus

115 peccavit, quia omni bono habundavit. Eciam alio modo offendens in uno factus est omnium reus, quia omnis virtus patitur detrimentum ab uno vicio; nam si quis incidat in avariciam, largitatem destruit, et eciam castitatem minoravit: amore enim pecunie vel violaret castitatem, vel saltem minus amaret. Si enim tanta propter Deum adhuc castitas inest, ut nolit eam perdere, saltem tamen

120 minori gaudio et minori affeccione tuetur eam, ubi videt procedere inde dampnum (V 57r) pecunie, sicque et in aliis, que etsi non expellantur, tamen percepcione unius vicii vel satis vel parum minuitur vel intencione deterioratur. Unde omnis virtus cuiuscumque criminis deflenda, et de omnibus indulgencia est petenda. Animadvertere eciam opportet et (P 154v) animadvertendo deflere

125 animam proximi, quam fornicator Deo eripuit vel ereptam in malo confirmavit, et quod exemplum extitit mali in operacione sui criminis, cui magis profuisset, si aliis causa fuisset conversionis. Gemat itaque aliorum vitam in sua corruptam vel incorruptam conservatam, et commodum proximi, quod dedisset exemplo boni. De tristicia doleat, quam bonis peccando intulit, et de leticia, quam eis

130 non adhibuit. Et non solum cogitet, quid et qualiter fecerit, sed quoniam iniuste Deum, ut diximus, peccando offenderit.

Timeat illam Veritatis sentenciam Non potestis duobus dominis servire. Timeat ergo, ne omnia bona, que fecit, dum in uno peccato perseveret, ex communicacione mali perdiderit, ut, qui servivit dyabolo per crimen, Deo quas obtulit, amiserit 135 virtutes. Pium tamen est credere, ut recepta gracia Dei, que in eo destruit mala, priora eciam (V 57v) remuneret bona, ut, cum destruxerit, quod suum non invenit, amet et diligat bonum, quod eciam in peccante plantavit.

In omnibus dolens aut seculum relinquat aut saltem, que sine ammixtione mali non sunt amministrata, ut mercatura et milicia, et alia, que utentibus sunt

$105 \mathrm{et}^{1}$ ] om. P || 106 est] om. P || 113 omnino] omnimodo P || 122 minuitur] minuuntur Fr, Wo; || deterioratur] deteriorantur Fr, Wo || 123 criminis] crimini Fr, Wo || 130 quoniam] quam P, Fr, Wo || 135 que - eo] om. $\mathrm{P}$ || 136 remuneret] remunerat $\mathrm{P}$ || 137 peccante] peccando $\mathrm{P}$

112 offendens - reus] $c f$ r. Iac 2,10 || 132 Non - servire] $c f$ r. Mt 6,24; Lc 16,13 
nociva, ut amministraciones secularium potestatum, nisi utatur hiis ex obediencia 140 licencie. Ponat se omnino in potestate iudicis, in iudicio sacerdotis nichil sibi reservans sui, ut omnia eo iubente paratus sit facere pro recipienda vita anime, quecumque faceret pro vitanda corporis morte, et hoc cum desiderio, quia vitam recuperat infinitam; cum gaudio enim facere debet inmortalis futurus, que faceret pro differenda morte moriturus. Semper deprecetur Deum, certus de venia, qui omnibus modis et sine dubio rogaret potestatem terrenam. Abstineat a multis licitis, qui in libertate arbitrii commisit illicita, semper offerat Deo mentem et cordis contricionem, deinde et, quod potest, de possessione - tunc, quod offerat, securus offerat: Respexit enim Dominus ad Abel et ad munera eius. Sed prius dicit "ad Abel”, quam "ad munera”; sumens (V 58r) enim mentem, quam cognovit humilem et puram, remunerat eius largitatis munera. Ad Cayn vero non respexit neque ad eius munera; mentem eius, quam viderat, quoniam non cognovit, eius munera non recepit. In iudicio itaque cordis consideranda est elemosina tribuentis, nec tam considerandum est quantum, sed qua mente, qua affeccione datur, quod potest - vidua enim duobus, que habuerat minutis, larga, plus omnibus posuit. Qui igitur peccata sua redimere vult temporalium oblacione, caveat: prius offerat mentem.

Cautus sit penitens, ne verecundia ductus dividat aput se confessionem, ut diversa diversis velit sacerdotibus manifestare: quedam enim celant uni, que alii manifestanda conservant, quod est se laudare et ad ypocrisim tendere et semper venia carere, ad quam per frusta totam pervenire putat. Paveat preterea, quem vera delectat penitencia: non prius ad Domini corpus accedat, quam confortet ipsum bona consciencia; sed in hac separacione tremendum iudicium cogitet, ubi maius et terribilius inpenitentes separabit in ignem; doleat, quod non audeat sumere, quem multum desiderat, cibum salutarem. (V 58v) Isti sunt digni fructus penitencie animam captivam elaqueantes et in libertate servantes.

Cohibeat se preterea a ludis, a spectaculis seculi, qui perfectam vult consequi graciam remissionis. Nam si Dina se cohibuisset, si inter suos remansisset, ab (P 155r) extraneo raptore corrupta non esset. Tanto itaque magis sibi caveat et cohibeat se anima, que semel rapta et est corrupta; timeat iam dicta experimento, quod ignoravit virgo. Eligat, quem imitetur, non sequatur, que animus suus dampnat. Se enim iudicat, qui penitencie fructum non habentem a se non

$\mathbf{1 4 1}$ potestate] potestatem $\mathrm{P}|| \mathbf{1 4 4}$ infinitam] infinitam ut deus $\mathrm{P} \| \mathbf{1 5 0}$ quam $^{2}$ ] quod V || $\mathbf{1 5 0}$ mentem] propter mentem ("propter" textui insertum) P; mentem enim Fr, Wo || 151 munera] verba P || 155 datur] dat Fr, Wo || 155 omnibus] omnibus aliis P || $\mathbf{1 5 8}$ penitens] penitus P || $\mathbf{1 6 1}$ frusta] frustra P || $\mathbf{1 6 2}$ penitencia] om. P || 168 si $^{2}$ - remansisset] om. V || 169 magis] magna P || 170 dicta] docta Fr, Wo

$\mathbf{1 4 9}$ Respexit - eius] Gn 4,4 || $\mathbf{1 5 1}$ / $\mathbf{1 5 2}$ Ad - munera] Gn 4,5 || $\mathbf{1 5 5}$ / $\mathbf{1 5 6}$ vidua - posuit] cfr. Mc 12,42- 43; Lc 21,2-3 || 165 / 166 digni - penitencie] $c f r$ Lc 3,8 || 168 / 169 Dina - esset] $c f r$. Gn 34,1-2 
elongat, laudat enim et amat, quos digne fructificare non ignorat. Querite fructus dignos, etsi non dignos penitencie: sunt enim digni fructus virtutum fructus, qui

175 non sufficiunt penitentibus; penitencia enim graviores expostulat, ut sic placetur ecclesia, ut placata dolore et gemitibus mortuis impetret vitam."

\section{$<\mathrm{III}>$}

Sapiencie $\mathrm{VI}^{\circ}$ capitulo

180 Audite ergo reges et intelligite, discite, iudices finium terre, prebete aures vos, qui continetis multitudines et placetis vobis in turbis nacionum, quoniam data est a Domino potestas vobis et virtus ab Altissimo, qui (V 59r) interrogabit opera vestra et cogitaciones scrutabitur. Quoniam cum essetis ministri regni illius, non recte iudicastis neque custodistis legem iusticie neque secundum voluntatem Dei ambulastis. Horrende et

185 cito apparebit vobis, quoniam iudicium durissimum in hiis, qui presunt, fiet. Exiguo enim conceditur misericordia, potentes autem potenter tormenta pacientur.

Ezechielis XLV ${ }^{\circ}$ capitulo

De terra erit eis possessio in Israel, et non depopulabuntur ultra principes populum meum, sed terram dabunt domui Israel secundum tribus eorum. Hec dicit Dominus

190 Deus. Sufficiat vobis, principes Israel. Iniquitatem et rapinas intermittite, iudicium et iusticiam facite. Separate confinia vestra a populo meo, ait Dominus Deus.

$<\mathrm{IV}>$

Noe primus vineam plantavit; inebriatus obdormivit denudatus, quem 195 primogenitus filius derisit, secundogenitus operuit et texit.

Noe designat Cristum, nam sicut Noe in mundi reformacione plantavit vineam post diluvium, sic Cristus plantavit ecclesiam (V 59v) post diluvium Veteris legis transgressorum. Vinea igitur est ecclesia, que tot palmites, quot electos ab Abel iusto usque ad ultimum electum produxit. Vinum vero saguinem Cristi demonstrat,

200 inebriacio spiritualem inebriacionem figurat amoris, quo Cristus inebriatus obdormivit in cruce denudatus. Derisio primogeniti derisionem significat Iudeorum et infidelium ceterorum, quia crucifixio Cristi Iudeis quidem scandalum, gentilibus autem stulticia videtur. Unde Iudei, qui fuerunt primogeniti Dei filii adoptivi, ipsum Filium Dei denudatum in cruce deriserunt. Secundogenitus 205 populum fidelem designat Cristi sanguine redemptum. Coopertura est caritas - hac fideles Cristum cooperiunt, quando pauperes nudos tegunt, iuxta illud

173 Querite] Querit P, Querat Fr, Wo || 174 etsi - dignos] om. V || 175 graviores] mores V, P, emendavi secundum Fr, sic et Wo I| $\mathbf{1 7 5}$ placetur] pacetur Fr, paccetur Wo I| 176 placata] peccata V, P; paccata Fr, Wo, emendavi; ||dolore] dolo P || 179 Sapiencie - capitulo] rubrica V, in marg. P || 181 placetis] placitis $\mathrm{P}$ || 187 Ezechielis - capitulo] rubrica $V|| 190$ Israel] om. P; || iudicium] et iudicium P, Vulg,Wo || 194 primus] primis P || 198 electos] dilectos P || 199 demonstrat] designat (demonstrat cancellatum) P || 201 significat] signat P || 202 infidelium ceterorum] ceterorum infidelium P

180 / 186 Audite - pacientur] Sap 6,2-7 || 188 / 191 De - Deus] Ez 45,8-9 || 194 Noe - plantavit] $c f r$. Gn 9,18-25 || 202 / 203 crucifixio - stulticia] $c f r$ I Cor 1,23 || 
"Quod minimis meis fecistis, michi fecistis". Hec est illa coopertura fervide caritatis, que operit Cristum in pauperibus et multitutinem tegit peccatorum.

Hec est moralizacio domini Karoli, regis Romanorum.

Tubalchaym primus artes, fabrilem et melodicam, invenit, atque per fabrilem ad 210 melodicam devenit. Nam per ferri concussionem (V 60r) deprehendit sonorum proporcionem, et percepit armonicam delectacionem. Iste Tubal(P 155v)chaym est figura hominis iusti et fidelis, cuius caro pro statu incipiencium per ferrum designatur, quia sicut durum est ferrum et tamen per malleacionem disponitur ad formas diversas nec non ad sonos formandos coaptatur, ita caro dura est ad percipiendam spiritualem delectacionem. Ferrum igitur carnalem designat naturam, malleacio vero corporis castigacionem figurat sive maceracionem, quia sicut ferrum sine ignili calore nequit duci bene sive disponi, sic nec hominis caro potest macerari sine igne caritatis.

Melodia spiritualem signat delectacionem et supernam, unde sicut ille Tubalchaym, primus faber, per ferri artacionem invenit et percepit melodicam delectacionem, sic homo fidelis in statu proficiencium per corporis maceracionem pervenit ad intellectum eternarum melodiarum et supernorum delectacionem in statu perfectorum.

Enoch, ut legitur in Genesi, primo cum Deo abiit et rediit, secundo abiit et non (V 60v) rediit. Enoch naturam designat humanam, quoniam natura humana primo quidem abiit cum Deo pro statu innocencie in primis parentibus, sed, heu, rediit in hunc mundum et miserie statum per peccatum. Verum post assumpcionem nature humane in unitatem suppositi divini humanum genus abiit cum Deo in Cristi ascensione, quando ascendens in altum captivam duxit captivitatem, et tunc non rediit amodo ad culpe et miserie statum. Et sicut Enoch revertetur ad iudicandum Anticristum, ita Cristus revertetur ad iudicandum mundum.

Iste sunt moralitates domini Karoli Romanorum et Boemie regis.

$\langle\mathrm{V}\rangle$

O Maria, cella Verbi incarnati, tu puteus, in quo hausit humana natura aquam vivam, salientem in eternum. Tu clarissimus virginitatis berillus, in cuius puritate sol divinitatis suos radios effudit, ex quorum reverberacione illuminate sunt tenebre nostre et eorum calore incensa sunt humana corda, ut urantur in caritate Dei. Tu

$209 \mathrm{Hec}$ - Romanorum] rubrica V, in $\mathrm{P}$ deest || 210 invenit] om. V || 212 armonicam] armoniacam P || 234 Iste - regis] rubrica $\mathrm{V}$, in $\mathrm{P}$ deest $\| \mathbf{2 3 8}$ berillus] rivulus $\mathrm{P}$

207 Quod - fecistis ${ }^{2}$ ] || cfr. Mt 25,40 || 208 multitutinem - peccatorum] $c f r$ I Pt 4,8 || 210 Tubalchaym] cfr. Gn 4,22 || 225 Enoch - Genesi] cfr. Gn 5, 21-24; cfr Eccli 44,16; Hbr 11,5 || 230 / 231 ascendens captivitatem] Eph 4,8 || 232 Enoch - Anticristum] cfr. Veteris Testamenti pseudoepigraphum Librum I Henoch |। 237 / 238 aquam - eternum] $c f r$. Io 4,14 
vera figura aquillaris, que in pennis humilioris coloris alia animalia prevolat; sic tu virtute humilitatis supervolasti (V 61r) omnes choros angelorum. De quibus alis aquille, que date sunt mulieri parturienti, Iohannes in Apocalipsi vocavit, tu ergo sic exaltata in caritate solis fervendo ad instar aquille renovasti senectutem

245 tocius generis humani abluendo vetustatem lavacro regeneracionis. Tu vera mater gracie mutans nomen Eve, matris culpe, que nos peccato suo excecavit, tu nos tua prudencia caritativa illuminasti. Nam sicut aquilla opponit radiis solis pullos suos, sic nos tu fugata nubis veteris caligine vero soli opposuisti, ut fervore ipsius mortales nostri oculi illuminarentur. Quapropter filius tuus adoptivus, cui te Filius

250 tuus in cruce conmendavit, typum aquile coram te fert in signum humilitatis ac victorie, qui et palme virginitatis tue fuit lator.

\section{$\langle\mathrm{VI}\rangle$}

(P 156r) In principio erat Verbum et Verbum erat aput Deum et Deus erat Verbum.

255 In Patre erat Filius, qui est Verbum Patris, quod Verbum Deus erat. Non enim in solo pane vivit homo, sed ex omni verbo, quod procedit ex ore Dei. Spiritus hominis (V 61v) habet vivere in Verbo et ex Verbo, et ideo Salvator de Spiritu in Iohanne ait docebit vos omnem veritatem, quia de meo accipiet et annuncciabit vobis. Homo, cum habeat spiritum intelligencie boni et mali, quem inspiravit sibi

260 Creator in Verbo in consensu Spiritus sancti, dum dixit "Faciamus hominem ad ymaginem et similitudinem nostram", non solum potest vivere ex pane, sed ex pane Verbi, nec similiter humanitas potest sustinere solum Verbum, quia nondum implevit precepta Verbi. Sed opportet eum sumere et panem in Verbo, ut ea, que mens intelligencie capax non existit in Verbo, assequatur in fide in pane Verbi,

265 qui datus est nobis in verbo salutis, dum dixit: Quicumque manducaverit ex hoc pane, non morietur in eternum. Voluit autem uniri Verbum cum pane ac altitudinem divinam cum cibo nostre fragilitatis, qui noluit abhorrere esurientem, sed in tantum se humiliavit, ut ei semetipsum offerret in cibum, et qui non abhorruit pro eo Virginis uterum. Et non solum voluit pascere spiritum verbo, sed et fragilitatem 270 nostram pane materiali, quem panem per verbum in semetipsum mutavit, dum dixit: Hoc est corpus meum. Et cum oraret Patrem (V 62r) pro humanitate, ut clarificaretur, oravit pro nostra fragilitate, ut corroboraretur, dicens: Claritatem, quam dedisti michi, dedi eis, ut sint unum, sicut et nos unum sumus. Pater, quos dedisti

241 coloris] caloris P || 241 sic] sicut P || 246 / 247 nos ${ }^{2}$ ] voca nos V; voca nos tu P; om. Wo; emendavi || 247 illuminasti] nos illuminasti Wo emendans || 251 lator] $\mathrm{P}$, in pagina (155v) residua, in 7 lineis epitaphium metricum Sigismundi regis legitur, manu alia scriptum || 256 in] ex P || 260 Creator] Salvator P

$\mathbf{2 4 2 ~ / ~} 243$ quibus - Apocalipsi] cfr. Apc 12,13-14 || 244 ad - senectutem] cfr. Ps 102,5 || 245 lavacro regeneracionis] cfr. Ti 3,5 || $\mathbf{2 4 9} / \mathbf{2 5 0}$ cui - conmendavit] cfr. Io 19,26-27 || 254 In - Verbum] Io 1,1 || 255 / 256 Non - Dei] $c f r$. Lc 4,4 (Dt 8,3) || 258 docebit - veritatem] Io 16,13 || 258 / 259 quia - vobis] Io 16,14 || 259 intelligencie - mali] cfr. Gn 2,9.17 || 260 / 261 Faciamus - nostram] Gn 1,26 || 265 / 266 Quicumque - eternum] Io 6,52 || 271 Hoc - meum] Mt 26,26; Mc 14,22; Lc 22,19; I Cor 11,24 || 272 ut clarificaretur] cfr. Io 17,1.5.10 || 272 / 273 Claritatem - sumus] Io 17,22 || 273 / 275 Pater - constitucionem] Io 17,24 
michi, volo, ut ubi sum ego, et illi sint mecum, ut videant claritatem meam, quam dedisti michi, quia dilexisti me ante mundi constitucionem.

$<$ VII $>$

Secundum Lucam

Factum est, dum iret Iesus in Ierusalem, transibat per mediam Samariam et Galileam. Et cum ingrederetur quoddam castellum, occurrerunt ei decem viri leprosi. Qui steterunt et levaverunt vocem dicentes "Iesu preceptor, miserere nostri!". Quos ut vidit, dixit: "Ite, ostendite vos sacerdotibus". Et factum est dum irent, mundati sunt. Unus autem ex illis, ut vidit, quia mundatus est, regressus est cum magna voce magnificans Deum, et cecidit in faciem ante pedes eius gracias agens - et hic Samaritanus. Respondens autem Iesus dixit: "Nonne decem mundati sunt? Et novem ubi sunt? Non est inventus, qui rediret et daret gloriam Deo nisi hic alienigena? Et ait illi: "Surge, vade, quia fides tua te salvum fecit."

(V 62v) Factum est, dum iret Iesus in Ierusalem, transibat per mediam Samariam et Galileam. Et cum ingrederetur quoddam castellum, occurrerunt ei decem viri leprosi. Et reliqua.

Fratres carissimi! Quia peccata, prochdolor, accumulans ab utero matris mee et ineuntis etatis primordiis adauxi frequenter et vitam celibem angelorum imitari nolui, mandatorum Dei transgressor, verbum Dei exponere, prout deceret, non valeo. Sed quia in nomine Iesu omne genu flectitur celestium, terrestrium et infernorum, ideoque intellectus meus, quamvis insufficiens, humiliato genu laudi tanti magnifici Creatoris deserviet, ut verba preassumpta sancti evangelii inbecillitate mea Spiritus sancti cooperante (P 156v) gracia exponantur. In cuius asspiracione benigna valeatis suscipere, quod sermone diserto non digne valeo declarare.

Igitur ad premissa sancti evangelii verba recurro beati Luce, qui dicit Factum est, dum iret Iesus in Ierusalem. Ista Ierusalem interpretatur "visio pacis", que visio pacis preordinata erat aput divinitatem ad pacificandum iram Dei contra humanum genus. In quo (V 63r) aspectu seu visu misericordie Dei fuit missus Filius, qui est Verbum Patris, et incarnatus ex Spiritu sancto transibat per mediam Samariam, que interpretatur "lana Domini" vel "coniunccio Domini" seu "custos" vel "custodiens Dominum". Nam dum assumpsit carnem ex Virgine, coniunxit deitatem cum humanitate, quia sicut lana aquam suscipit et remittit incorrupta, sic

$\mathbf{2 7 4}$ meam] magnam meam $\mathrm{P}$ || $\mathbf{2 7 8}$ Secundum Lucam] rubrica $\mathrm{V}$, in $\mathrm{P}$ deest || $\mathbf{2 8 0}$ steterunt] steterunt a longe Vulg; cfr. infra lin. 334 || $\mathbf{2 9 0}$ reliqua] reliqua. Omelia. P || $\mathbf{2 9 3}$ nolui] volui P || $\mathbf{2 9 4}$ flectitur] flectatur P || 297 cooperante] in pagina (156r) residua, in 7 fere lineis, nota de bello hussitico incohante legitur, manu alia scripta $\mathrm{P}$ । 300 / 301 que - pacis] om. P || 306 incorrupta] incorruptam P

279 / 287 Factum - fecit] Lc 17,11-19 || 294 in - infernorum] Phil 2,10 || 301 Ierusalem $^{2}$ - pacis] $c f r$. Heller, H 1296, p. 241-242 || 304 / 305 Samariam - Dominum] cfr. Heller, H 2571, p. 460 
Virgo Filium concepit et peperit sine corrupcione. Et in coniunccione humanitatis cum deitate non est ipsa humanitas a deitate confusa, sed clarificata secundum 310 illud Iohannis "claritatem dedi eis". Custos autem aut custodiens fuit Maria secundum illud Luce Maria autem conservabat omnia verba hec conferens in corde suo. Que lana sua contexit humanitatem cum deitate, cum dixit se ancillam Domini. - Et Galileam, que Galilea "rota" vel "volubilis" sive "transmeans" aut "transmigracio" interpretatur, Transitus iste per Galileam nobis clare ostenditur

315 in eo, cum transisset per auream portam Virginis lux et decus universe fabrice mundi, hoc est: cum de Virgine nasceretur, intravit in volubilitate rote nostre miserie (ut Iob: numquam in eodem statu permanet) (V 63v) transmeans per mortem, ut transmigraret per mortem in vitam.

Et cum ingrederetur quoddam castellum. Castellum autem, in quod ingressus

320 est, signat mundum istum. Nam iste mundus firmaverat sibi castrum, et contra divinam maiestatem erexerat turrim superbie, videlicet turrim Babel, prout in Genesi: Faciamus nobis civitatem et turrim, cuius culmen pertingat usque ad celum, et celebremus nostrum nomen. Et civitatem Babilon, illam magnam meretricem, intellige circumdata septem muris, qui erant septem peccata mortalia, que 325 eandem civitatem circuibant. Que peccata per septem capita bestie figurantur, quam vidit Iohannes in Apocalipsi dicens: Vidi bestiam habentem capita septem.

Occurrerunt ei decem viri leprosi. Decem viri leprosi, qui occurrerunt ei, significant humanum genus, quod maculatum erat lepra peccati peccando contra decem precepta Dei. Et in hoc representaret decem leprosos, qui occurrerunt ei, 330 quia ibi non erat medicus, qui curaret eos. Et ideo quoque dicti sunt viri, quia virilitatem habebant recedendi a peccato. Sed heu multi derelicta virilitate in pigricia et torpore obdormiunt in peccatis non (V 64r) curantes currere Domino obviam animarum querendo sanitatem.

Qui steterunt a longe: quoniam longe a peccatoribus salus, prout in ewangelio 335 Luce: Stans a longe publicanus non presumebat nec oculos suos ad celum levare etc. Et levaverunt vocem quasi ad celestem medicum, quia de terris medicus eos sanare non poterat, nec aliud est vocis elevacio nisi quedam suffragii postulacio de premiis. Dicentes "Iesu preceptor, miserere nostri". Ipsi evangelizaverunt eum preceptorem in aspiracione Spiritus sancti, cuius regnum et imperium sine fine 340 permanet, qui testis Patris fuit dilecti sui Filii. Et pecierunt misericordiam dicentes "miserere nostri", et in fide eorum salvavit eos. Quos ut vidit, dixit: "Ite, ostendite vos sacerdotibus," non quia ipse in eos potestatem non haberet, sed ut (P 157r)

310 aut] om. $\mathrm{P}|| \mathbf{3 1 2}$ / 313 se] se esse $\mathrm{P}|| \mathbf{3 1 7} \mathrm{ut}$ ] pro $\mathrm{V}|| \mathbf{3 2 0}$ mundum istum] istum mundum $\mathrm{P}$ || 324 intellige] om. P || 326 quam] que P || 326 dicens] om. P || 328 significant] signant P || $\mathbf{3 3 0}$ medicus] medicus manens $\mathrm{P}|| \mathbf{3 4 2}$ eos] ipsos $\mathrm{P}$

310 claritatem - eis] cfr. Io 17,22 || 311 / 312 Maria - suo] Lc 2,19 || 312 / 313 ancillam Domini] cfr. Lc 1,38 || 313 / 314 Galileam - interpretatur] cfr. Heller, H 666, p. 137 || 317 numquam - permanet] Iob 14,2 || 322 / 323 Faciamus - nomen] Gn 11,4 || 323 Babilon - meretricem] cfr. Apc 17,1.5 || 326 Vidi - septem] Apc 13,1 || 334 longe $^{2}$ - salus] Ps 118,155 || 335 Stans - levare] Lc 18, 13 
sacerdotum dignitatem honoraret, qui summus sacerdos erat, sed veram hostiam adhuc non ymmolaverat, scilicet suum sacratissimum corpus in ara crucis, qui intendebat prius animas a lepra peccati salvare quam corpora, et ideo misit eos ad sacerdotes, ut se eis ostenderent, qui lepram humanitatis in se assumpserat et voluit in ( $\mathbf{V}$ 64v) passione et saguine suo humanitatis nostre lepram peccatumque sanare. Et factum est dum irent: per hoc in salutis exemplum insinuatur eorum obediencia. Mundati sunt: hic ostenditur divine gracie affluencia. Unus autem ex illis, ut vidit, quia mundatus est, regressus est cum magna voce magnificans Deum et cecidit in faciem ante pedes eius gracias agens; et hic Samaritanus, qui interpretatur lana vel coniunccio seu custos aut custodiens. Iste Samaritanus significat Cristum, qui coniunxit divinitatem cum humanitate, custos divinitatis et custodiens humanitatem. Respondens autem Iesus dixit: "Nonne decem mundati sunt? Et novem ubi sunt? Non est inventus, qui rediret et daret gloriam Deo, nisi hic alienigena?" In hoc alienigena representatur Cristi persona. Nam novem sunt chori angelorum et decimus divine essencie, de qua essencia processit Filius Dei, qui est Verbum Patris, et assumpsit fragilitatis nostre carnem factus leprosus propter nos, nam languores nostros ipse portavit (ut ait propheta), reputavimus eum tamquam leprosum et percussum a Deo et humiliatum, et ipsam carnalem (V 65r) nostram infirmitatem nobiscum portavit, donec clarificaret eam in sua resurreccione. Pro qua claritate gracias Patri egit solus, qui alienigena erat nec de foribus angelorum vel nostris. Actamen nos, qui sumus filii Ade, quos creavit Pater celestis ad reimplendum novem choros angelorum, quamvis sanati fuissemus cum eo in passione sua a lepra per Deum, et expectaremus, sicut hodie expectamus, inibi mansiones perpetuas, nullus nostrum reddidit grates Deo Patri pro sanitate nostra nisi ipse solus Filius Dei, qui erat alienigena de decimo choro divine essencie. Dicat nunc hereticus : "Cur Pater ab arce non misit Verbum, id est Filium, ad sanandam lepram malorum angelorum sicut hominum?" Et respondeat iudex: "Ipsi divinam essenciam viderunt, seducti non fuerunt, corrupcione caruerunt, humana vero natura in fragilitate Ade incepta divinitatem non vidit, sed in similitudine humani generis Deum vidit, preceptum ipsius ex animali seduccione infregit ac penam pro eo a Deo deputatam portavit, nec tamen ipse transgressor cum semine suo dignus fuit reparare mandati Dei transgressionem. Ideo (V 65v) providit Deus de reparacione per Filium suum, ad cuius similitudinem hominem creaverat, quem voluit ex homine nasci, id est de Virgine corpus humanum assumere, qui in suam claritatem nos omnes vocavit secundum illud Iohannis claritatem, quam dedisti michi, dedi eis, ut sint unum, sicut

353 significat] signat P; || qui] cum P || 365 fuissemus] fueramus P || 367 grates] gracias P || 372 vidit] vivit $\mathrm{P}$

$\mathbf{3 5 9}$ / $\mathbf{3 6 0}$ languores - humiliatum] Is 53,4 || $\mathbf{3 7 8}$ / $\mathbf{3 7 9}$ claritatem - sumus] Io 17,22 
et nos unum sumus. Et cum transivisset per Samariam et assumpsisset vestitum de

380 lana humanitatis nostre, et pertransisset Galileam, scilicet per volubilitatem istius mundi, captivam duxit secum nostre humanitatis captivitatem. Et sicut cum veteri Adam genus humanum de paradiso terrestri fuit expulsum ex culpa, sic cum isto Adam novo fuit in paradisum celestem reductum ex gracia. Et hanc graciam visionis pacis previderat cum Patre et Spiritu sancto in celesti Ierusalem,

385 que vere est visio pacis eterne, ubi Deus omnem abstergit lacrimam, ut non sit amplius luctus neque dolor, hoc est in sublimitate archani celestis, priusquam in terrenam Ierusalem introiret.

Aliter eciam potest dici Nonne decem mundati sunt etc.: Decem sunt precepta Dei, IX precepta in decimo precepto, scilicet in dileccione Dei, comprehenduntur.

390 Et illa dileccio (V 66r, P 157v) sive caritas sola refert gracias Deo, et graciam a Domino promeretur, ut ait Apostolus: Si liguis hominum loquar et angelorum, caritatem autem non habeam, nichil sum. Secundum preceptum dileccionis proximi est adeo consilium carni; sufficiebat enim in dileccione Dei, quia qui precipit spiritui, precipit et carni, nam qui Deum vere diligit, diligit et creaturam Dei

395 et omnia ei cooperantur in bonum, et in ipsa dileccione Dei perfecte manendo non desinit referre gracias Deo. Et ideo sola dileccio Dei refert gracias, quia alienigena est nec de foribus nostris, quia qui Deum diligit, hunc mundum odit et non est de mundo; ideo mundus habet eum odio, quia Deum priorem odio habuit. Et ideo spirituale est istud preceptum et maius omnibus secundum illud

400 horum autem maior est caritas, alia autem precepta sunt consilia carni, que eciam gentiles tenent et secuntur non propter Deum, sed propter carnem et saguinem: diligunt proximum, fugiunt homicidium, non furantur, quia ius naturale est "quod tibi non vis, alteri non feceris".

$405<$ VIII >

(V 66v) O mira res! Creator perdidit dilectum primum creatum exaltatum pre omnibus creaturis suis, clarissimum Luciferum, ex mira bonitate sua creatum, per ipsius Luciferi ingratitudinem superbam divini iudicii missum in infernum cum suis complicibus. Quis condoluit Creatori? Bone creature, Michael et alii 410 secum in gracia, veritate et caritate permanentes, sed eorum consilium solum non poterat prebere reparamentum. Incitat ergo Creatoris potestas Verbum sue sapiencie in bonitate Pneumatis almi ad reparacionem curie celestis ordinate

380 Galileam] per Galileam P || 384 previderat] providerat || P || 385 abstergit] abstersit P || 394 spiritui] spiritum P || 396 referre gracias] gracias referre P

381 captivam - captivitatem] $c f r$ Eph 4,8 || 385 / 386 omnem - dolor] $c f r$ Apc 21,4 || 389 in ${ }^{1}$ - Dei] $c f r$.

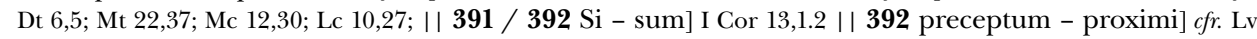
19,18; Mt 22,39; Mc 12,31; Lc 10,27 || 395 omnia - bonum] Rm 8,28 || 397 / 398 mundum - mundo] $c f r$ Io 17,14-16; || 397 / 398 mundus - odio ${ }^{1}$ ] cfr. I Io 3,13 || 400 horum - caritas] I Cor 13,13 || 401 carnem saguinem] $c f r$. Mt 16,17 || 403 quod - feceris] $c f r$ Tb 4,16; Mt 7,12; Lc 6,31 || 
aciei per inordinacionem turbate, ut non tedeat supernos cives amisisse partem creaturarum Creatoris sui. Dixit ergo Creator: Faciamus hominem ad ymaginem et similitudinem nostram. Licet ibi crearet primum Adam, dixit tamen de secundo Adam in parte, cum dixit "ad ymaginem et similitudinem nostram". Nam Filio data fuit potestas in celo et in terra a Patre, et erat Verbum Patris, quod incarnatum fuit de Spiritu sancto, qui est amor procedens ab utroque. Sed quia primus Lucifer, creatus in purissimis naturalibus, superbivit, creavit primum Adam ex terra figuli, quod est vilius inter (V 67r) elementa, ut non opponeret se Creatori recordans, quod illam purissimam creaturam habuit potestatem condempnandi. Sed ille invidissimus amissor parte regni sui, invidus et sevus, suggestione falsa mulierem decepit et eum per consequens in tantum, ut deiceretur Dei vero iudicio de paradiso. Recordatus autem consilii sui, quod habuit in archano sue deitatis, cum vidisset hominem lapsum fragilitate et insipiencia sua credentem demoniacis verbis, et non malicia, sicut dyabolus se opposuerat, recordatus est, unde eum fecerat, et adhibuit potenciam contra infirmitatem, sapiencaim contra insipienciam, bonitatem Spiritus sancti contra dyaboli maliciam Et misit secretum suum paranimphum, ut superbum dyabolum infatuaret contra maliciam suam ad virginem, ex genere Ade fragili natam et in veste testea figuli obumbravit, cum angelo peregisset legacionem et virginis habuisset consensum. Et quia dyabolus superbiam preposuerat sibi et cum Deo ipse superbiendo contenderat, putabat Omnipotentem sibi dominari superbe; sed quia Sapiencia, quod est Verbum Patris, vincit maliciam, quod est mendacii verbum, et sibi contrariantur, (V 67v) voluit illud Verbum, quod est Filius, in controversia superbiam dyaboli humilitate superare, et ideo sumpsit de carne nostra humanitatem in testa figuli et in olla figuli obumbravit lucem suam. Et ipse dyabolus ex ignorancia ollam contempnens cooperator et inductor (P 158r) fuit facture olle et vasis testeis, quousque confractum fuit et lux emanans excecavit eum, et fulgur choruscans et vox tonitrui sui in rota confregit tarthara, ita ut non remaneret sibi potestas in illis, qui non ex sanguinibus nec ex voluntate carnis, sed ex Deo nati sunt.

Et post quadraginta dies reformatam nostram humanitatem destructa captivitate duxit in celum, ubi glorificata sedet ad dexteram Dei Patris, pro qua oraverat in terris adhuc existens dicens Patri: Clarifica Filium tuum, et alibi "clarifica et eos, qui in me credituri sunt". Ipse autem victor ascendit, inimicum

413 turbate] turbatam V, P, Wo; emendavi || supernos] super nos P || 415 crearet primum] primum crearet $\mathrm{P}$ || 430 testea] om. V || obumbravit] obumbravit eam Wo emendans || 433 dominari] dominare P || 441 sunt] om. P || 443 Dei Patris] Patris Dei P

414 / 415 Faciamus - nostram] Gn 1,26 || 417 data - terra] cfr. Mt 28,18 430 obumbravit] cfr. Lc 1,35 || 431 angelo - consensum] $c f r$. Lc 1,38 || 439 / 440 fulgur - rota] $c f r$. Ps 76,19 || 441 qui - sunt] $c f r$. Io 1,13 || 442 quadraginta - celum] $c f r$. Act 1,2-11 || 443 ad - Patris] $c f r$ Rm 8,34; Eph 1,20 || 444 Clarifica - tuum] Io 17,1 || 445 clarifica - sunt] $c f r$. Io 17,20 
antiquum serpentem debellatum proiecit in profundum vocans humiles et eos collocans in eternis sedibus, a quibus superbi rebellantes demones ex malicia ceciderunt.

$450 \quad\langle\mathrm{IX}>$

Leccio sancti ewangelii secundum Lucam

(V 68r) In illo tempore extollens vocem quedam mulier de turba dixit ad Iesum: "Beatus venter, qui te portavit, et ubera, que suxisti" et reliqua. Omelia.

Cum Dominus Iesus in digito Dei mutum demonium eiecisset, et quod fortem 455 armatum humani generis inimicum ipse forcior superveniens arma eius auferens et spolia distribuens vinceret, populis predicaret, ut sic eos ad appetenda et speranda gaudia celestia, que suasu serpentino per Evam perdiderant, revocasset, quedam mulier de turba in admiracione extulit vocem dicens: "Beatus venter, qui te portavit, et ubera, que suxisti." Quasi diceret "ex beata matre natus es,

460 qui revocas exules filios Eve”. Et benedixit ventrem et ubera, insinuans, quod hic nove matris Filius est Deo dilectus. Et ideo per muliebrem sexum facta fuit hec exclamacio, quia mulier Adam primum hominem quasi pomo vescendo dyaboloque consenciendo mortis fuit cooperatrix genus humanum servituti peccati subieciendo, et econverso mulier benedicta Deo complacendo ipsumque 465 lacte suo pascendo fuit vite auxiliatrix in relevando genus humanum.

Ubera quoque laude (V 68v) digna erant, que paverunt eum, qui venit omnes pascere sua gracia, quos mundus non potest saciare sua avaricia. Animadvertamus autem, qua temeritate Adam terrenus superbivit, dum a muliere pomo pasci voluit cupiens diis assimilari, et qua benignitate se Deus humiliavit, ut homo fieret et 470 pasceretur lacte mulieris. Consideremus Adam, quando fructum arboris spoliate a muliere recepit, aspiciamus Deum, quomodo a muliere carnem susceptam arbori loco fructus ablati restituit.

Et quia mundus non pollicebatur premium sempiternum, et iste, qui clausus fuerat in ventre matris, promittebat vitam eternam, ideo venter laude dignus erat, 475 qui donatorem tanti doni in se clauserat, quia quem celi capere non poterant, Virgo gloriosa suo gremio inclusit. Ista mulier, que exclamavit, potest assimilari ecclesie, quam dignatus est Dominus vocare sponsam suam, nam sicut hec mulier benedixit eum in veritate, sic ecclesia eum cottidie benedicit in verbo suo, de quo verbo ipse ait mulieri et similiter ecclesie: Beati, qui audiunt verbum Dei

451 Leccio - Lucam] rubrica $\mathrm{V}$, in $\mathrm{P}$ deest $\| 452$ vocem] om. $\mathrm{P} \| 453$ Omelia] rubrica $\mathrm{V}$, in $\mathrm{P}$ deest $\|$ 454 demonium] dominium $P$ || 458 extulit] extolit P || 462 vescendo] pascendo P || 463 servituti] servitute P || 466 Ubera] Verba V, P, Wo, coniecit Mašek || 472 restituit.] restituit. Tu autem V, P, Wo 476 assimilari] assimilare $\mathrm{P}$

446 antiquum - proiecit] $c f r$. Apc 12,9; 20,2 || 452 / 453 extollens - suxisti] Lc 11,27 || 454 Dei - eiecisset] cfr. Lc 11,14 || $\mathbf{4 5 4}$ / $\mathbf{4 5 5}$ fortem armatum] $c f r$. Lc 11,21 || $\mathbf{4 5 5}$ / $\mathbf{4 5 6}$ forcior - vinceret] $c f r$. Lc 11,21-22 || 469 cupiens - assimilari] $c f r$ Gn 3,5 || 479 / 480 Beati - illud] Lc 11,28 || 
et custodiunt illud. Ecclesia autem audit ( $\mathbf{V}$ 69r) et custodiendum pronuncciat 480 dicens: Nunc ergo, filii, audite me: beati, qui custodiunt vias meas.

481 Nunc - meas] Prv 8,32 
